\title{
Precipitation in Highly Supersaturated Al-Sc-V, Al-Sc-Nb, and Al-Sc-Ta Alloys During Isochronal Aging
}

\author{
Keith E. Knipling ${ }^{1}$ \\ ${ }^{1 .}$ U. S. Naval Research Laboratory, Multifunctional Materials Branch, Washington, DC 20375
}

Conventionally solidified Al-Sc alloys, strengthened by nanoscale $\mathrm{Al}_{3} \mathrm{Sc}\left(\mathrm{Ll}_{2}\right.$ structure) precipitates, have excellent coarsening and creep resistance to $300{ }^{\circ} \mathrm{C}[1,2]$, and can be improved up to $400{ }^{\circ} \mathrm{C}$ with ternary additions of the neighboring Group 4 elements, Ti [3] $\mathrm{Zr}$ [4,5] or Hf [6]. These ternary solutes have a much smaller diffusivity than $\mathrm{Sc}$ [1], resulting in $\mathrm{Al}_{3} \mathrm{Sc}_{1-x} \mathrm{M}_{x}(\mathrm{M}=\mathrm{Ti}, \mathrm{Zr}$, or Hf) precipitates with a Sc-rich core enveloped in a $\mathrm{Zr}$, Ti, or Hf-enriched shell. These slower-diffusing atoms limit coarsening and, since they substitute for Sc in the precipitates, can also reduce the relatively high cost of Sc additions.

The Group 5 elements in the periodic table $(\mathrm{M}=\mathrm{V}, \mathrm{Nb}$, or $\mathrm{Ta})$ may also be beneficial alloying additions to Al-Sc alloys. They each form an $\mathrm{Al}_{3} \mathrm{M}$ trialuminide and also exhibit some solubility in $\mathrm{Al}_{3} \mathrm{Sc}$ [7], and are anticipated to be much slower diffusers than $\mathrm{Ti}, \mathrm{Zr}$, or Hf [1], potentially providing better thermal stability than Al-Sc-Ti, Al-Sc-Zr, or Al-Sc-Hf alloys. This study investigates the nanostructures and compositions of $\mathrm{Al}_{3} \mathrm{Sc}_{1-x} \mathrm{M}_{x}$ precipitates formed in highly supersaturated $\mathrm{Al}-\mathrm{Sc}-\mathrm{V}, \mathrm{Al}-\mathrm{Sc}-\mathrm{Nb}$, and Al-ScTa alloys during isochronal aging from 200 to $500{ }^{\circ} \mathrm{C}$.

The Al-0.4Sc-0.4V, Al-0.4Sc-0.4Nb, and Al-0.4Sc-0.4Ta (all compositions are in at.\%) alloys were first dilution cast from binary master alloys using non-consumable electrode arc-melting in a high-purity argon atmosphere. After arc-melting, a $\sim 7 \mathrm{~g}$ portion of each ingot was melt-spun by induction melting in a quartz crucible under a $34 \mathrm{kPa}$ helium atmosphere and ejecting the melt through a $1.0 \mathrm{~mm}$ orifice onto the perimeter of a copper wheel rotating at a surface speed of $20 \mathrm{~m} \mathrm{~s}^{-1}$. The ribbons produced were typically $3-5 \mathrm{~mm}$ wide, $50 \mu \mathrm{m}$ thick, and several centimeters long. Prior to aging, the ribbons were encapsulated in quartz ampoules that had been evacuated and backfilled with high-purity argon to $\sim 34$ $\mathrm{kPa}$. The encapsulated alloys were aged isochronally in $25^{\circ} \mathrm{C}$ increments lasting $3 \mathrm{~h}$ each, starting at $200^{\circ} \mathrm{C}$ and terminating at $500^{\circ} \mathrm{C}$. The quartz ampoules were water-quenched between each aging increment. Since the solute concentrations in these alloys far exceed their equilibrium maximum solid solubilities, the specimens were not solution treated prior to precipitation aging. The microstructures that formed upon aging were investigated by atom-probe tomography (APT) with a Cameca LEAP 4000x Si. Specimens for APT were prepared using standard lift-out and focused ion beam (FIB) milling procedures [8] in an FEI Nova 600 NanoLab DualBeam ${ }^{\mathrm{TM}} \mathrm{SEM} / \mathrm{FIB}$.

An atom-probe reconstruction of the Al-Sc-V alloy aged to $500{ }^{\circ} \mathrm{C}$ is displayed in Figure $1(\mathrm{a})$, with each $\mathrm{Sc}$ atom represented as a blue pixel, $\mathrm{V}$ atoms with red pixels, and $\mathrm{Si}$ atoms with gray pixels (Al atoms are not shown for clarity). The presence of $\mathrm{Si}$ is a byproduct of melting each ingot in a quartz crucible during melt spinning. The APT analysis shown partially intercepted three $\sim 12-15 \mathrm{~nm}$ diameter $\mathrm{Al}_{3} \mathrm{Sc}_{1-}$ ${ }_{x} \mathrm{~V}_{x}$ precipitates. While virtually all of the $\mathrm{Sc}$ segregates to the precipitates, a significant amount of $\mathrm{V}$ remains in $\alpha$-Al solid-solution, as evidenced by the predominance of red $\mathrm{V}$ atoms in the matrix surrounding the precipitates. This is conveyed quantitatively in Figure 1(b), which is a proxigram [9] displaying average solute concentration profiles in the $\alpha$-Al matrix and $\mathrm{Al}_{3} \mathrm{Sc}_{1-x} \mathrm{~V}_{x}$ precipitates with respect to a 2.5 at.\% Sc isoconcentration surface delineating the two phases. Sc, V, and Si segregate to 
the $\mathrm{Al}_{3} \mathrm{Sc}_{1-x} \mathrm{~V}_{x}$ precipitates. As in prior APT studies on Al-Sc-Ti, Al-Sc-Zr, and Al-Sc-Hf alloys [3-6], the $\mathrm{V}$ atoms constitute a small fraction of the precipitate and are segregated at the $\alpha-\mathrm{Al}_{1} / \mathrm{Al}_{3} \mathrm{Sc}_{1-x} \mathrm{~V}_{x}$ precipitate interface, suggesting that $\mathrm{V}$ is much slower diffuser than Sc. The $\alpha-\mathrm{Al}$ solid-solution contains $0.0145(5)$ at. $\% \mathrm{Sc}, 0.675(3)$ at.\% $\mathrm{V}$, and $0.356(2)$ at.\% Si. While the solubility of $\mathrm{V}$ in $\alpha-\mathrm{Al}$ is not known below $600{ }^{\circ} \mathrm{C}$, the equilibrium maximum solid solubility is 0.33 at.\% $\mathrm{V}$ at $662.1{ }^{\circ} \mathrm{C}$ [1], which is less than half the concentration of V measured in Figure 1(b). Thus, the $\alpha$-Al solid-solution is metastably supersaturated in $\mathrm{V}$, indicating that equilibrium has not yet been reached after aging to 500 ${ }^{\circ} \mathrm{C}$. This is consistent with the expected extraordinarily sluggish diffusion kinetics of the Group 5 solutes in Al.

References:

[1] K Knipling et al, International Journal of Materials Research 97 (2006), p. 246.

[2] J Royset and N Ryum, International Materials Reviews 50 (2005), p. 19.

[3] M van Dalen et al, Acta Materialia 53 (2005), p. 4225

[4] C Fuller et al, Acta Materialia 51 (2003), p. 4803.

[5] C Fuller and D Seidman, Acta Materialia 53 (2005), p. 5415.

[6] H Hallem et al, Materials Science and Engineering A 421 (2006), p. 154.

[7] Y Harada and D Dunand, Materials Science and Engineering A 329 (2002), p. 686.

[8] K Thompson et al, Ultramicroscopy 107 (2007), p. 131.

[9] O Hellman et al, Microscopy and Microanalysis 6 (2000), p. 437.

[10] This work was funded by the Naval Research Laboratory under the auspices of the Office of Naval Research. Dr. Nhon Q. Vo (nanoAl) is thanked for his assistance with thermal aging of the alloys.
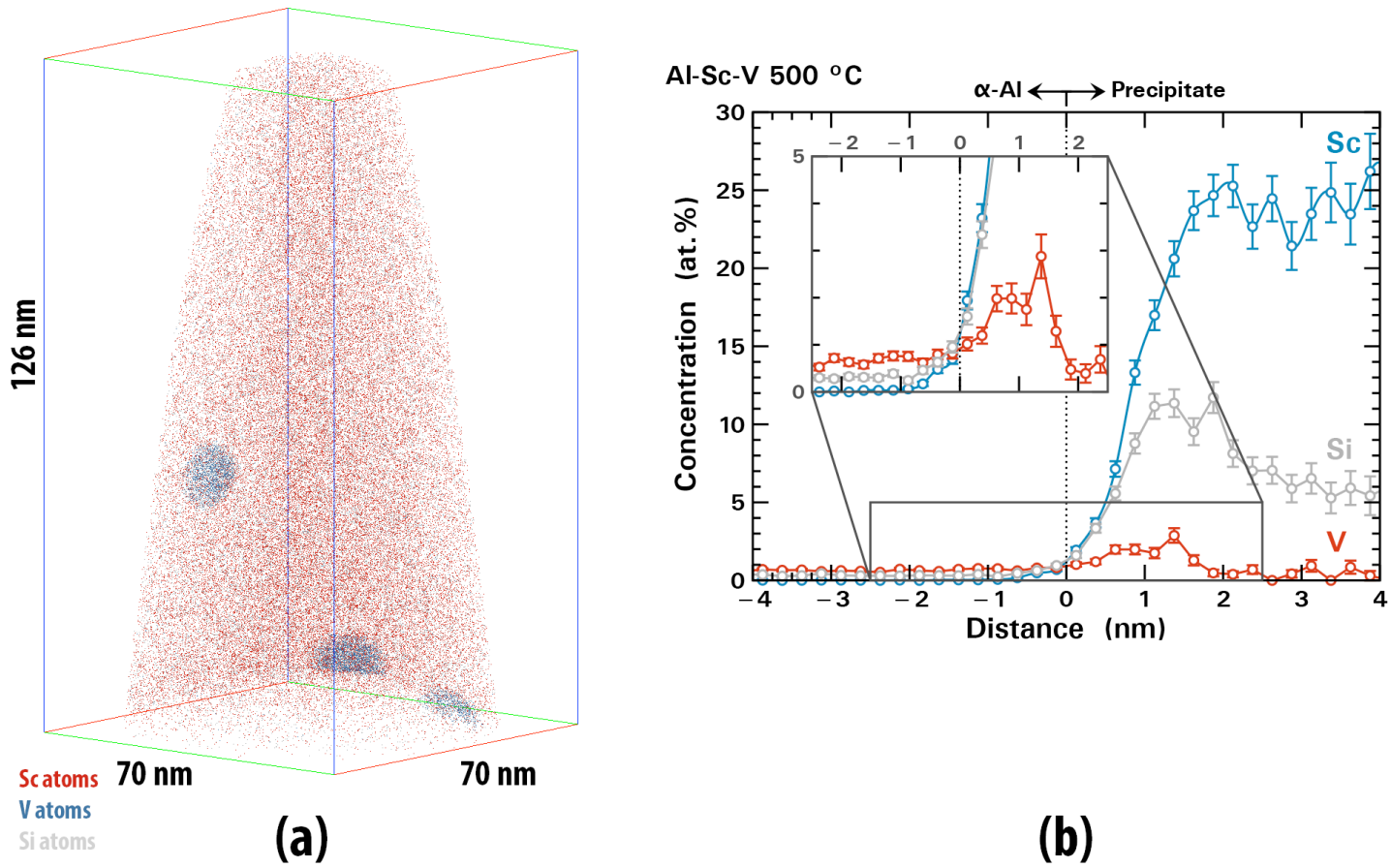

(b)

Figure 1. (a) APT reconstructions of the Al-Sc-V alloy isochronally aged to $500{ }^{\circ} \mathrm{C}$, containing three $\sim 12-15 \mathrm{~nm}$ diameter $\mathrm{Al}_{3} \mathrm{Sc}_{1-x} \mathrm{~V}_{x}$ precipitates. (b) Proxigram displaying the distributions of $\mathrm{Sc}, \mathrm{V}$, and $\mathrm{Si}$ atoms in the $\mathrm{Al}_{3} \mathrm{Sc}_{1-x} \mathrm{~V}_{x}$ precipitates and the $\alpha$-Al solid-solution. 